\title{
Localization of angiotensin receptor type 2 in fetal bovine ovaries
}

\author{
V.M. Portela ${ }^{\mathrm{a}, *}$, A.C. Castilho ${ }^{\mathrm{b}}$, K. Bertolin ${ }^{\mathrm{a}}$, J. Buratini Jr. ${ }^{\text {c }}$, C.A. Price ${ }^{\mathrm{a}}$ \\ a Centre de Recherche en Reproduction Animale, Faculté de Médecine Vétérinaire, Université de Montréal, St-Hyacinthe, Quebec, Canada \\ b Departamento de Farmacologia, Instituto de Biociências, Universidade Estadual Paulista, Botucatu, São Paulo, Brazil \\ c Departamento de Fisiologia, Instituto de Biociências, Universidade Estadual Paulista, Botucatu, São Paulo, Brazil
}

\section{A R T I C L E I N F O}

\section{Article history:}

Received 11 November 2014

Received in revised form 13 January 2016

Accepted 24 February 2016

Available online 10 March 2016

\section{Keywords:}

Preantral follicle

AT2

Angiotensin

Ovigerous chord

Fetal ovary

\begin{abstract}
A B S T R A C T
In the ovary, angiotensin II (ANGII) acts through the type 2 receptor (AGTR2) to induce ovulation and may play a role in follicle atresia. In this study, we determined the expression of AGTR2 mRNA and protein during follicle formation in the bovine ovary. Female fetuses at different gestational ages $(60,75,90,120,150$ and 210 days $)$ were used for immunolocalization of AGTR2. At day 60, AGTR2 was localized to the cytoplasm of oogonia; from days 75 to 150, during follicle formation and development to secondary stage, AGTR2 immunostaining was weak and irregular, but from day 210 staining became evident in granulosa cells of preantral follicles and in both granulosa and theca cells of small antral follicles. These data differ from those in pigs, in which AGTR2 protein is detected in preantral follicles throughout gestation. Abundance of AGTR2 mRNA in whole ovaries did not change with fetal age. In conclusion, AGTR2 protein is expressed in ovigerous cords in fetal bovine ovaries but not in preantal follicles until the formation of antral follicles. These data suggest important species-specific differences in the expression of AGTR2 in fetal ovaries from polyovulatory and monovulatory animals.
\end{abstract}

(c) 2016 Elsevier B.V. All rights reserved.

\section{Introduction}

In cattle, ovarian folliculogenesis begins during fetal development (Tanaka et al., 2001). Primordial follicles, composed of an oocyte surrounded by squamous pregranulosa cells, are observed from approximately day 75 of fetal life in Bos indicus cattle. By day 90, primary follicles develop, characterized by a single layer of cuboidal granulosa cells. The development of a second layer of granulosa cells marks the formation of secondary follicles, which occurs from day 150 of fetal life. Antral follicles are observed from day 210

\footnotetext{
* Corresponding author at: Centro Curitibanos, Universidade Federal de Santa Catarina, Curitibanos, Santa Catarina, Brazil.

E-mail addresses: valerio.portela@ufsc.br, valerio.portela@gmail.com (V.M. Portela).
}

of fetal development (Castilho et al., 2014). The regulation of preantral follicle development is poorly understood, although several paracrine signaling molecules have been implicated. These include members of the transforming growth factor $§$ family, the fibroblast growth factor family and kit ligand (Buratini and Price, 2011).

Another potential signaling molecule is angiotensin II (ANGII), which acts through two transmembrane receptors. The effects of ANGII on blood pressure are via the type 1 receptor (AT1) whereas other actions are believed to be via the type 2 receptor (AGTR2) (Paul et al., 2006). Within the ovarian follicle, AGTR2 protein is generally found in the granulosa cell layer, although there appear to be species differences in the precise pattern of localization. In rabbits, AGTR2 is expressed in granulosa cells of preovulatory follicles, consistent with the role of ANGII in ovulation (Kuji 


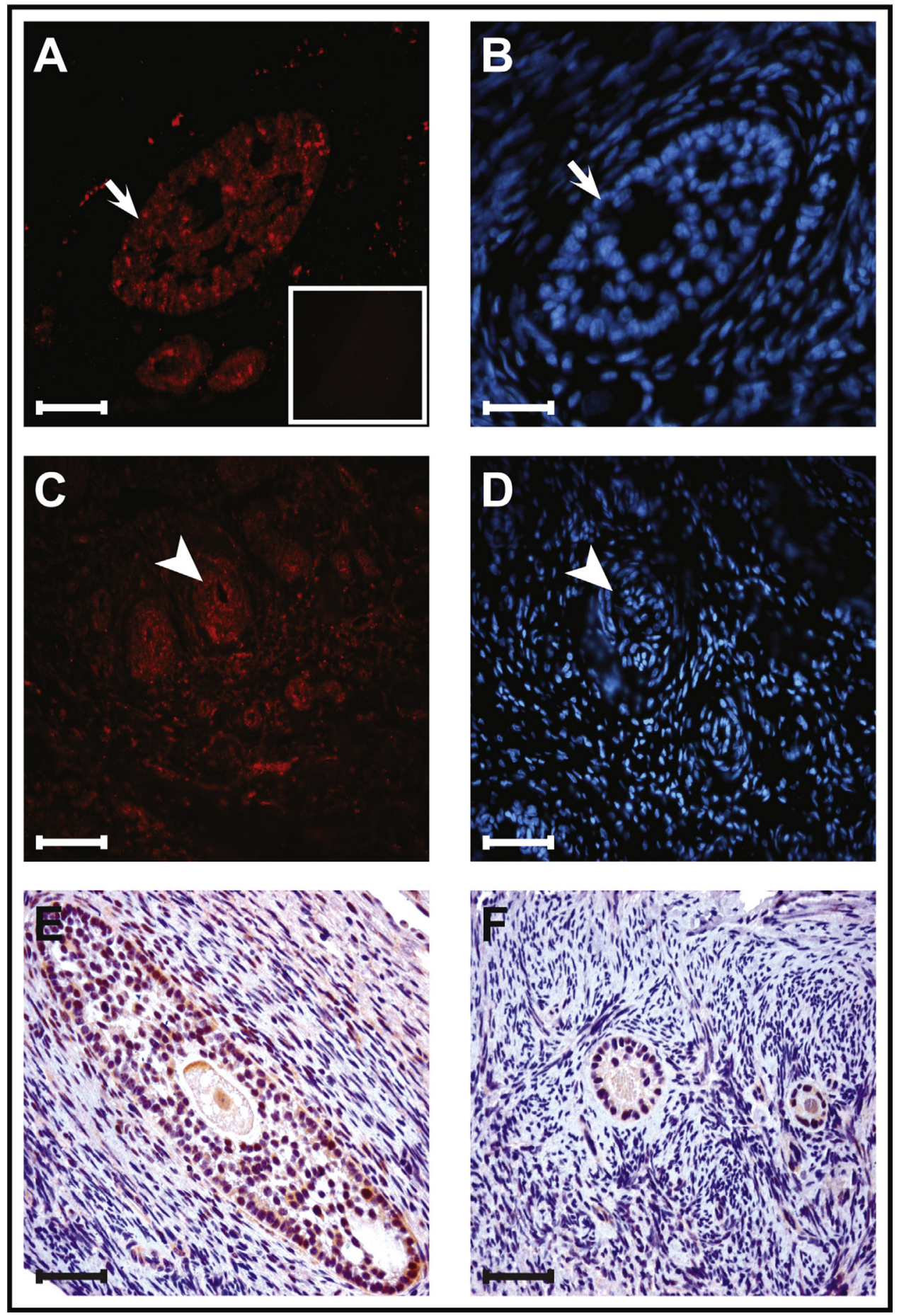

Fig. 1. Localization of AGTR2 protein in preantral follicles of adult ovaries. A and B, immunofluorescent detection of AGTR2 in primary and secondary follicles (A) and DAPI staining in the same section (B). The inset in A is an adjacent section processed in the absence of AGTR2 antibody and shows weak background fluorescence. (C), ovarian blood vessels stained for AGTR2, and the same field stained for DAPI (D). (E) and (F), colorimetric immunostaining of secondary and primary follicles confirms the localization observed by immunofluorescence. Photomicrographs were taken at $\times 400$ magnification; bars $=40 \mu \mathrm{m}$.

et al., 1996), whereas in rats and pigs AGTR2 was located to granulosa cells but only in atretic follicles (Daud et al., 1988; Pucell et al., 1991; Shuttleworth et al., 2002; de Gooyer et al., 2004). Cattle appear to be different, as AGTR2 has been localized to theca cells in some studies (BrunswigSpickenheier and Mukhopadhyay, 1992; Acosta et al., 1999; Schauser et al., 2001) and to both granulosa and theca cells in another study (Portela et al., 2008). We found that the 
60 days $\mathrm{GA}$
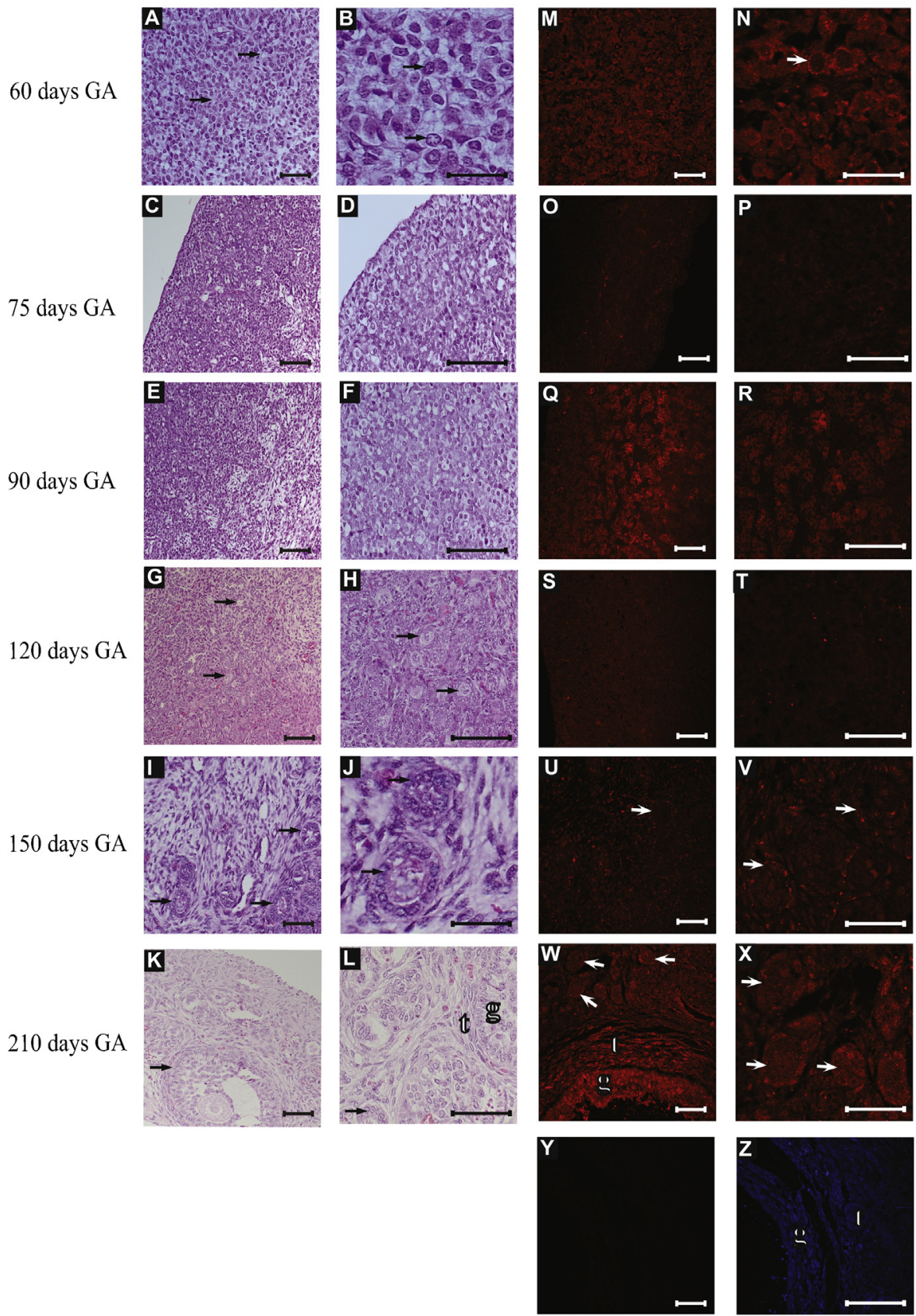

Fig. 2. Histological and immunohistochemical analysis of AGTR2 protein in bovine fetal ovary. (A) and (B), histological analysis revealed the presence of ovigerous cords (arrows, A) at gestational age (GA) of 60 days, containing oogonia (arrows, B) and pregranulosa cells; AGTR2 staining was observed in the oogonia (G, H). (C) and (D), on day 150, ovarian histology shows the formation of primary follicles (arrows, C) surrounded by granulosa cells (arrows, D); these follicles did not stain for AGTR2 (I, J). Antral follicles were seen on day 210 of fetal age, as well as the other follicular stages (t, theca cells; $g$, granulosa cells; arrows, preantral follicles); staining for AGTR2 is present in theca and granulosa layers of antral follicles (K) and preantral follicles (L, arrows). (M) and $(\mathrm{N})$, Negative control in the absence of AGTR2 antibody. Bars $=40 \mu \mathrm{m}$.

pattern of expression in granulosa cells in cattle appears to be the reverse of that in rats and pigs, as AGTR2 mRNA expression was lower in atretic compared to healthy granulosa cells in vivo (Portela et al., 2008).
There are few studies of the expression of ANGII receptors in the developing ovary. In fetal pig ovaries, AGTR2 protein was detected in ovigerous chords but was weak to undetectable in the preantral follicle in one study (Shuttleworth et al., 2002), whereas a later study from the 
same laboratory detected AGTR2 protein in preantral follicles throughout gestation (Pountain et al., 2010). As far as we are aware, there are no reports of the expression of AGTR2 protein/mRNA in the fetal ovary of other species, and given the discrepancy in the literature regarding the localization of AGTR2 receptors in cattle (theca or granulosa), the objective of the present study was to determine if AGTR2 protein is detectable in the fetal ovary and whether localization in the bovine follicle changes during follicle formation.

\section{Materials and methods}

\subsection{Tissues}

Female cow fetuses (predominantly Nelore-Bos indicus) were obtained from an abattoir local to the Sao Paulo State University campus in Botucatu. Fetal age was estimated by crown-rump length (Rüsse, 1983) and ovaries were classified into six groups according to gestational age $(60,75,90,120,150$ and 210 days of gestation, $n=5$ /group). Ovaries from adult cattle at random stages of the estrous cycle were obtained from an abattoir local to the Faculté de médecine vétérinaire, Université de Montréal, and the ovarian cortex was recovered. Tissues were fixed in $10 \%$ formaldehyde solution and embedded in paraffin for histology and immunohistochemistry.

\subsection{Histology and immunohistochemistry}

Tissue sections ( $3 \mu \mathrm{m}$ ) were mounted on poly-L-lysine coated slides, deparaffinized in xylene twice for $30 \mathrm{~min}$, and hydrated in successive 5 min washes in 95\% followed by $85 \%$ ethanol. Formaldehyde was removed from the sections by incubation in 10\% ammonium hydroxide in ethanol for $10 \mathrm{~min}$, followed by rinsing in distilled water. For histology and immuno-detection of AGTR2, four fields were examined in three sections from each of three fetuses at each age. To determine follicle development at each age, sections were stained with hematoxylin and eosin and examined under light microscope at $100 \times$ magnification. The number of primordial (oocyte associated with squamous pregranulosa cells), primary (oocyte surrounded by a single layer of cuboidal granulosa cells), secondary (oocyte surrounded by at least two layers of granulosa cells) and antral follicles were determined.

For immunofluorescence, antigen retrieval was achieved by boiling in $0.01 \mathrm{M}$ sodium citrate and $0.1 \mathrm{M}$ citric acid for $5 \mathrm{~min}$. Sections were blocked in 10\% normal goat serum for $1 \mathrm{~h}$ and then incubated with 1:300 rabbit anti-sheep AGTR2 (cat. 19134; Abcam Inc, Cambridge, MA, USA) for $18 \mathrm{~h}$ at $4 \mathrm{C}$. Slides were washed in PBS and then incubated with Cy3-conjugated second antibody (Jackson ImmunoResearch, West Grove, PA) and counterstained with DAPI. Adjacent sections were used for negative controls (absence of primary antibody) and routine $\mathrm{H} \& \mathrm{E}$ staining by the histopathology service of the Faculté de médecine vétérinaire. Immunofluorescence was observed by confocal microscopy using the Olympus Fluoview 1000 system and Fluoview version 1.7 software. Laser sources of $543 \mathrm{nM}$ and $405 \mathrm{nM}$ were employed for detection of CY3 and DAPI signals, respectively. For a given fluorochrome (i.e., CY3 or DAPI), photomultiplier voltage, laser power, pinhole aperture, time of acquisition and image resolution were maintained constant for all confocal images. The Kalman filter mode was used for all image acquisition.

Further sections were examined by immunohistochemistry, performed using the primary antibody as described above. The slides were washed in PBS and then incubated with biotinylated second antibody for $45 \mathrm{~min}$. After two 5 min washes in PBS, a complex of avidin-peroxidase was applied for $45 \mathrm{~min}$. Positive reactions were revealed by NovaRED (Vector Labs, Burlingame CA) staining. Sections were then rinsed in distilled water and counterstained with hematoxylin for $10 \mathrm{~s}$. Negative controls were performed simultaneously in the absence of primary antibody.

\subsection{Nucleic acid extraction and reverse transcription-polymerase chain reaction ( $R T-P C R$ )}

Total RNA was extracted using Trizol according to the manufacturer's instructions, and quantified by absorbance at $260 \mathrm{~nm}$. Total RNA (1 $\mu \mathrm{g})$ was first treated with $1 \mathrm{U}$ DNase (Promega, Madison, WI) at $37^{\circ} \mathrm{C}$ for $30 \mathrm{~min}$ to digest any contaminating DNA, followed by adding $1 \mu$ l of EDTA stop buffer at $65^{\circ} \mathrm{C}$ for $10 \mathrm{~min}$. The RNA was reverse transcribed in the presence of $1 \mathrm{mM}$ oligo(dT) primer and $4 \mathrm{U}$ Omniscript RTase (Omniscript RT Kit, Qiagen, Mississauga, ON), $0.25 \mathrm{mM}$ dideoxy-nucleotide triphosphate (dNTP) mix, and 19.33 U RNase Inhibitor (GE Healthcare, Baie D’Urfé, QC) in a volume of $20 \mu \mathrm{l}$ at $42^{\circ} \mathrm{C}$ for $2 \mathrm{~h}$. The reaction was terminated by incubation at $93^{\circ} \mathrm{C}$ for $5 \mathrm{~min}$.

Real-time PCR was performed with a 7300 Real-Time PCR System (Applied Biosystems, Foster City, CA) using Power SYBR Green PCR Master Mix (Applied Biosystems) and bovine-specific primers for amplifying cyclophilin $A$ (PPIA; sense: 5'- GCCATGGAGCGCTTTGG-3', anti-sense: 5'-CCACAGTCAGCAATGGTGATCT-3'), AGTR2 (sense: 5'GACCTGGCACTTCCTTTTGC-3', antisense: 5'- GGAGCTTCTGCTGGAACCTATTC $-3^{\prime}$ ) and the plasminogen activator inhibitor, SERPINE2 (Bédard et al., 2003). The qPCR conditions were $3 \mathrm{~min}$ at 95C followed by 40 cycles of $15 \mathrm{~s}$ at $95 \mathrm{C}, 30 \mathrm{~s}$ at $60 \mathrm{C}$ and $30 \mathrm{~s}$ at $72 \mathrm{C}$. Melting curve analyses were performed according to manufacture's conditions to verify the RT-PCR reaction specificity. Samples were run in duplicate, and PPIA served as a reference gene. Data were normalized to a calibrator sample using the $\Delta \Delta \mathrm{CT}$ method with correction for amplification efficiency (Pfaffl, 2001).

\subsection{Statistical analysis}

Data that did not follow a normal distribution (ShapiroWilk test) were transformed to logarithms. Homogeneity of variance was tested with O'Brien and Brown-Forsythe tests. Analysis of data was performed with JMP software (SAS Institute) with treatment or follicle group as main effect and culture replicate (where appropriate) as a random variable in the F-test. Differences between means were tested with the Tukey-Kramer HSD test. Data are presented as means \pm SEM. 
Table 1

Occurrence of AT2 immunostaining in ovaries of individual fetuses.

\begin{tabular}{llll}
\hline & Sample 1 & Sample 2 & Sample 3 \\
\hline 60 days & ++ & ++ & ++ \\
75 days & - & - & - \\
90 days & + & + & - \\
120 days & - & - & - \\
150 days & + & + & - \\
210 days & ++ & ++ & ++ \\
\hline
\end{tabular}

++, staining evident; +, weak staining; -, no staining.

\section{Results and discussion}

In adult ovaries, immunofluorescence indicated the presence of AGTR2 protein in the granulosa cell layer of primary and secondary preantral follicles (Fig. 1A,B,E) and in blood vessels (Fig. 1C,D). No staining was evident in the stroma or negative controls (Fig. $1 \mathrm{~A}$ insert) and, importantly, there was no staining in the developing theca layer surrounding the secondary follicle. Staining was evident in granulosa and theca cells of antral follicles (not shown). These data are consistent with our previous observation of AGTR2 protein in the granulosa and theca cell layers of antral follicles in cattle (Portela et al., 2008), although the absence of AGTR2 protein in the theca layer forming around secondary follicles suggests that expression of this gene is developmentally regulated.

In order to identify at which stage of follicle development AGTR2 protein is expressed, we performed immunofluorescence analysis of fetal ovaries. Day 60 fetal ovaries contained ovigerous cords and no follicles. Primordial follicles were first observed on Day 75 ovaries, primary follicles on Day 90 ovaries, and secondary follicles were not observed until Day 150 (Table 1). This pattern of follicle development is similar to that previously described in (Castilho et al., 2014).

Immunostaining for AGTR2 protein was detected in the cytoplasm of oogonia of Day 60 fetuses (Fig. 2 G-H), and became weak and irregular in all slides evaluated from Day 75 through day 150 (Fig. 2C-D to I-J). Temporally, AGTR2 protein was not detected again until Day 210 (Fig. 2E-F), when granulosa cells of primary (Fig. $2 \mathrm{~K}-\mathrm{L}$ ) and secondary follicles were immunopositive, as were both granulosa and theca cells of antral follicles. The staining in fetal primary and secondary follicles at this stage is consistent with that observed in adult cattle.

The weak and irregular staining during the stages of primordial and primary follicles contrasts with the convincing immunostaining observed by Pountain et al., 2010 in primordial and primary follicles of fetal pig ovaries. One explanation may be the different pattern of follicle development of these species in utero; developmentally, primary follicles appear earlier in the cow (day 90; 0.3 gestation) than in the pig (day 90; 0.8 gestation) (Oxender et al., 1979; Rüsse, 1983; McCoard et al., 2003; Yang and Fortune, 2008), as do secondary follicles ( 0.5 gestation in the cow and term in the pig).

Abundance of mRNA encoding AGTR2 in whole ovaries did not change along the time-points studies here (Fig. 3A), although there was a tendency for higher levels on day 75. In pigs, Pountain et al., 2010 observed a significant

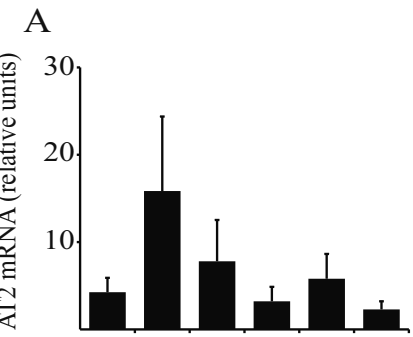

B

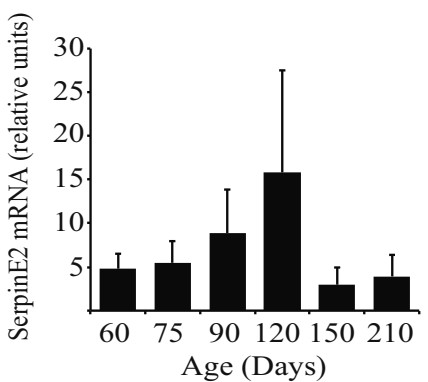

Fig. 3. Relative abundance of (A) AGTR2 and (B) SERPINE2 mRNA in whole ovaries of bovine fetuses on days $60,75,90,120,150$ and 210 of gestation $(n=3-4)$. Data were obtained by real-time PCR and are expressed as mean $\pm \mathrm{SEM}$ relative abundance $(\mathrm{ddCt})$.

decline in AGTR2 mRNA levels at the time of appearance of primary follicles (day 75-90); this would correspond to the (non-significant) decline in mRNA levels observed here between day 75 and 120 . The mRNA levels in whole ovaries do not reflect well protein levels detected by immunofluorescence, and changes in cell populations during ovarian development may have altered the number of different cell types contributing RNA to the sample. It is not known how this might impact levels of housekeeping and target genes.

One potential role for ANGII is modulating tissue remodeling events in the fetal ovary, as it has been shown to suppress expression of the protease inhibitor SerpinE2 in granulosa cells (Portela et al., 2008). In the present study, SerpinE2 mRNA abundance exhibits an inverse profile when compared to AGTR2 expression over the period of primary follicle formation, from day 75-120, although this was not significant. These findings warrant further investigation in follicles rather than whole ovarian tissue.

In conclusion, AGTR2 protein is expressed in ovigerous cords in fetal bovine ovaries, but is it not localized to primordial and primary follicles after oocyte nest breakdown. This is in contrast to the pig, in which AGTR2 protein is present in preantral follicles throughout fetal development, and suggests a potentially important species-specific difference between polyovulatory and monovulatory animals.

\section{Conflict of interest}

There is no conflict of interest.

\section{Acknowledgements}

The authors thank the Natural Science and Engineering Research Council (Canada) and Fundação de Amparo à 


\section{Pesquisa do Estado de São Paulo (Brazil) for supporting this study.}

\section{References}

Acosta, T.J., Berisha, B., Ozawa, T., Sato, K., Schams, D., Miyamoto, A., 1999. Evidence for a local endothelin-angiotensin-atrial natriuretic peptide systemin bovine mature follicles in vitro: effects on steroid hormones and prostaglandin secretion. Biol. Reprod. 61, 1419-1425.

Bédard, J., BrÛlé, S., Price, C.A., Silversides, D.W., Lussier, J.G., 2003. Serine protease inhibitor-E2 (SERPINE2) is differentially expressed in granulosa cells of dominant follicle in cattle. Mol. Reprod. Dev. 64, 152-165.

Brunswig-Spickenheier, B., Mukhopadhyay, A.K., 1992. Characterization of angiotensin-II receptor subtype on bovine thecal cells and its regulation by luteinizing hormone. Endocrinology 131, 1445-1452.

Buratini, J., Price, C.A., 2011. Follicular somatic cell factors and follicle development. Reprod. Fertil. Dev. 23, 32-39.

Castilho, A.C., da Silva, R.B., Price, C.A., Machado, M.F., Amorim, R.L., Buratini, J., 2014. Expression of fibroblast growth factor 10 and cognate receptors in the developing bovine ovary. Theriogenology $81,1268-1274$.

Daud, A.I., Bumpus, F.M., Husain, A., 1988. Evidence for selective expression of angiotensin II receptors on atretic follicles in the rat ovary: an autoradiographic study. Endocrinology 122, 2727-2734.

de Gooyer, T.E., Skinner, S.L., Wlodek, M.E., Kelly, D.J., Wilkinson-Berka, J.L., 2004. Angiotensin II influences ovarian follicle development in the transgenic (mRen-2) 27 and Sprague-Dawley rat. J. Endocrinol. 180, 311-324.

Kuji, N., Sueoka, K., Miyazaki, T., Tanaka, M., Oda, T., Kobayashi, T., Yoshimura, Y., 1996. Involvement of angiotensin II in the process of gonadotropin-induced ovulation in rabbits. Biol. Reprod. 55, 984-991.
McCoard, S.A., Wise, T.H., Ford, J.J., 2003. Germ cell development in Meishan and White Composite gilts. Anim. Reprod. Sci. 77, 85-105.Oxender, W.D., Colenbrander, B., van deWiel, D.F.M., Wensing, C.J.G., 1979. Ovarian development in fetal and prepubertal pigs. Biol. Reprod. 21, 715-721.

Paul, M., Poyan Mehr, A., Kreutz, R., 2006. Physiology of local renin-angiotensin systems. Physiol. Rev. 86, 747-803.

Pfaffl, M.W., 2001. A new mathematical model for relative quantification in real-time RT-PCR. Nucleic Acids Res. 29, e45.

Portela, V.M., Gonçalves, P.B.D., Veiga, A.M., Nicola, E., Buratini Jr., J. Price, C.A., 2008. Regulation of angiotensin type 2 receptor in bovine granulosa cells. Endocrinology 149, 5004-5011.

Pountain, S.J., Broughton Pipkin, F., Hunter, M.G., 2010. The ontogeny of components of the renin-angiotensin system in the porcine fetal ovary. Anim. Reprod. Sci 117, 119-126.

Pucell, A.G., Hodges, J.C., Sen, I., Bumpus, F.M., Husain, A., 1991. Biochemical properties of the ovarian granulosa cell type 2-angiotensin II receptor. Endocrinology 128, 1947-1959.

Rüsse, I., 1983. Oogenesis in cattle and sheep. Bibl. Anat. 24, 77-92.

Schauser, K.H., Nielsen, A.H., Winther, H., Dantzer, V., Poulsen, K., 2001. Localization of the renin-angiotensin system in the bovine ovary: cyclic variation of the angiotensin II receptor expression. Biol. Reprod. 65, 1672-1680.

Shuttleworth, G., Hunter, M.G., Robinson, G., Broughton Pipkin, F., 2002. Immunocytochemical localization of angiotensin II receptor subtypes 1 and 2 in the porcine fetal, prepubertal and postpubertal ovary. J. Anat. 201, 267-274.

Tanaka, Y., Nakada, K., Moriyoshi, M., Sawamukai, Y., 2001. Appearance and number of follicles and change in the concentration of serum FSH in female bovine fetuses. Reproduction 121, 777-782.

Yang, M.Y., Fortune, J.E., 2008. The capacity of primordial follicles in fetal bovine ovaries to initiate growth In vitro develops during mid-gestation and is associated with meiotic arrest of oocytes. Biol. Reprod. 78, 1153-1161. 